\title{
In-situ Characterization of Metals in the Polymeric Films with Optical Beam Microanalysis
}

\author{
F.-H. Ko, and P.-H. Chi
}

Institute of Nanotechnology, National Chiao Tung University, 1000, Ta-Hsueh Road, Hsinchu 300, Taiwan

The characterization of metallic impurity in polymeric films is very important for IC industry. The impurity existing in the polymeric films can migrate into the underlying substrate during baking process and deteriorate the device reliability. The in-situ laser ablation inductively coupled plasma mass spectrometry (LA-ICP-MS) possesses the advantages of better sensitivity and higher throughput. In this study, we use the Nd-YAG laser, operated under either Q-switched or free running mode, to ablate the film and detect with ICP-MS (in Fig. 1).

Figure 2 shows the SEM images of the laser-induced craters formed on the polymeric film under the $330 \mathrm{~mJ}$ laser beam energy. The images of ablated samples use only one laser pulse. The diameter of ablating region for free running mode is roughly one-half of that for Q-switched mode. The relatively small ablated area for the free running mode indicates limited energy dissipation on the polymeric film, and the formation of surface plasma is not observed for free running. The higher ablated density and the more ablated uniformity are seen for the Q-switched mode, and suggest its suitability for microanalysis. Previous investigators have noted the formation of plasma above the sample surface [1] for Q-switched operation, which enables a succeeding coupling to polymeric film and leads to melting and vaporization of the impact area.

The coating uniformity, baking temperature, and silicon substrate surface reflection, are investigated with respect to their effects on the microanalysis. In addition, the operating parameters such as beam energy, defocus, carrier gas flow rate and RF power are evaluated and optimized. The profiles of the ablation region at different operating conditions are recorded by SEM. Upon completing the optimization, the beam technique is applied for microanalysis. The results are illustrated in Table 1, and the analytical results for the various calibration methods are all in good agreement. The analytical throughput of the microanalysis was improved up to 12 samples per hour.

\section{Reference}

[1] J. Muramoto et al., Appl. Phys. Lett. 77 (2000) 2334. 


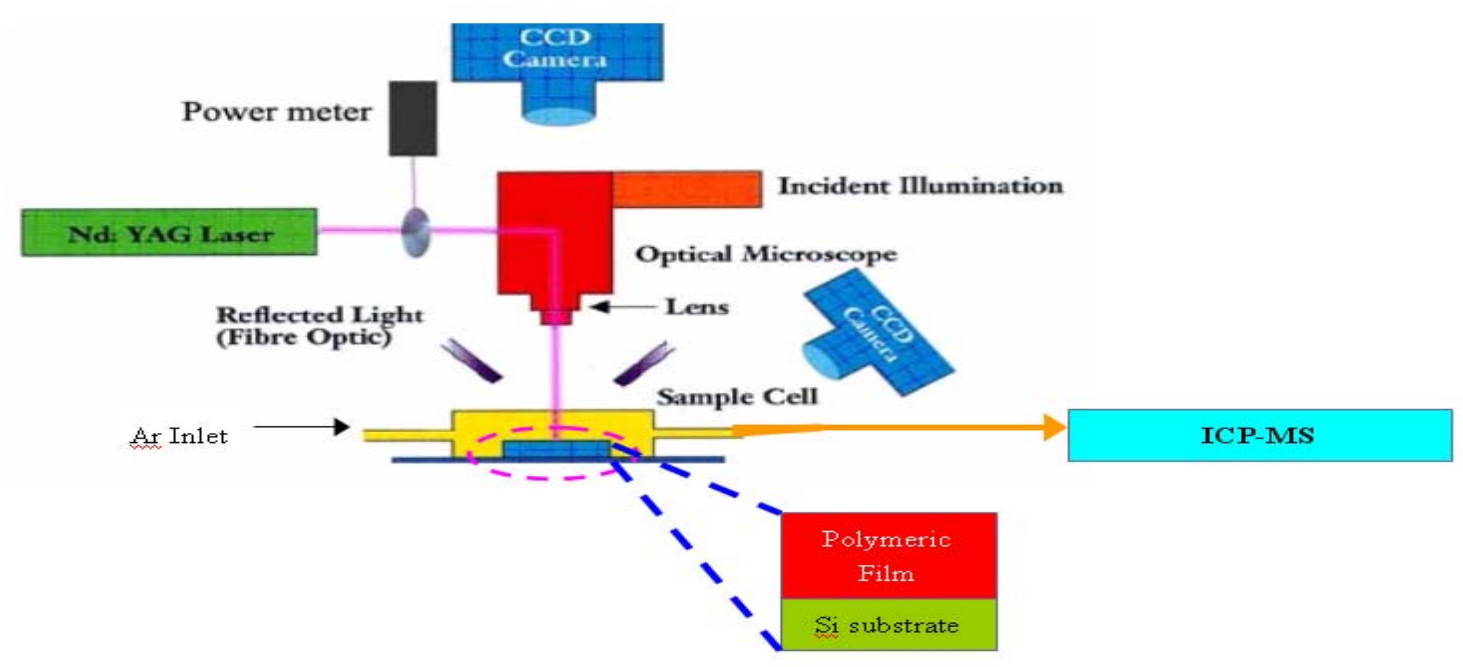

Fig. 1. Schematic diagram of laser beam microanalysis system.

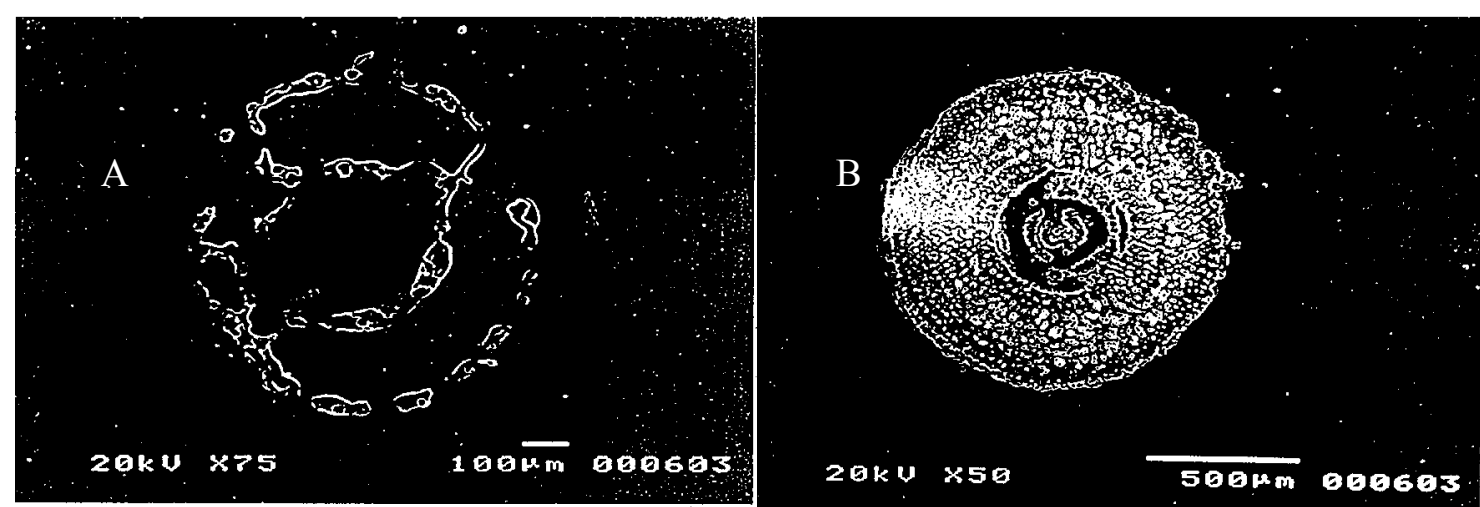

Fig. 2. SEM images of the polymeric films at different laser operation modes: (A) free running and (B) Q-switched.

Table 1. Analytical results for metal-spiked polymeric films with various methods; $n=3,7$ sites per sample, ablated by one laser pulse

\begin{tabular}{|c|c|c|c|c|c|c|c|c|}
\hline & \multicolumn{2}{|c|}{$\begin{array}{l}\text { nominal conc. } \\
\text { (ng/mL) }\end{array}$} & \multicolumn{2}{|c|}{$\begin{array}{l}\text { method 1a } \\
\text { (ng/mL) }\end{array}$} & \multicolumn{2}{|c|}{$\begin{array}{l}\text { method } 2^{b} \\
\text { (ng/mL) }\end{array}$} & \multicolumn{2}{|c|}{$\begin{array}{l}\text { method } 3^{c} \\
\text { (ng/mL) }\end{array}$} \\
\hline & high & low & high conc. & low conc. & high conc. & low conc. & high conc. & low conc. \\
\hline $\mathrm{Al}-27$ & 6740 & - & $6510 \pm 370$ & - & $6910 \pm 240$ & - & $6750 \pm 320$ & - \\
\hline $\mathrm{Cu}-63$ & 1410 & 500 & $1380 \pm 120$ & $550 \pm 147$ & $1410 \pm 120$ & $532 \pm 123$ & $1440 \pm 130$ & $562 \pm 127$ \\
\hline Pt-195 & 228 & 114 & $214 \pm 43$ & $132 \pm 47$ & $194 \pm 21$ & $102 \pm 13$ & $194+33$ & $144 \pm 44$ \\
\hline Au-197 & 228 & 114 & $240 \pm 31$ & $118 \pm 30$ & $227 \pm 40$ & $128 \pm 27$ & $214 \pm 30$ & $136 \pm 37$ \\
\hline Th-232 & 228 & 114 & $237 \pm 13$ & $104 \pm 22$ & $206 \pm 11$ & $93 \pm 14$ & $223 \pm 15$ & $118 \pm 21$ \\
\hline U-238 & 228 & 114 & $248+25$ & $133 \pm 22$ & $203 \pm 11$ & $96 \pm 13$ & $231+30$ & $148 \pm 28$ \\
\hline
\end{tabular}

"The method used extemal calibration curve. 'The method used C-13 as intemal standard. "The method used Co-59 as intemal standard for $\mathrm{Al}$ and $\mathrm{Cu}$, while $\mathrm{Tl}-205$ for $\mathrm{Pt}, \mathrm{Au}$, Th and $\mathrm{U}$. 